\title{
An Appraisal of Asia-Pacific Cities as Control and Command Centres Embedded in World City Network
}

\author{
Zeyun Li \\ Geography Section, School of \\ Humanities, Universiti Sains Malaysia \\ Penang, Malaysia \\ lizeyun@yahoo.com
}

\author{
Sharifah Rohayah Sheikh Dawood \\ Geography Section, School of \\ Humanities, Universiti Sains Malaysia \\ Penang, Malaysia \\ sdawood@usm.my
}

\author{
Xiaoxiao Zhang \\ TESOL, School of Educational Studies \\ Universiti Sains Malaysia \\ Penang, Malaysia \\ 2390965168zxx@gmail.com
}

\begin{abstract}
Since the globalization trend is proliferating at a staggering rate, world cities have emerged as the most dominant vanguard incorporated into global economy. Control and command function is one of the robust integral parts of world city formation, which is closely associated with the corporate headquarter status of some dominant multinational companies. Previous research works on this topic tend to concentrate on the Western Europe and North American arenas neglecting the AsiaPacific region. Hence, the objective of this paper is to explore control and command functions of Asia-Pacific cities with reference to headquarters' locations of multinational companies. The methodology will utilize the Forbes global 2000 dataset from the seminal study of GaWC research group, and apply the control and command center model and the interlocking city network model to discover the control and command index, as well as network connectivity of Asia-Pacific cities. Based upon the empirical study of this research, we could identify the hierarchical structure and spatial structure of Asia-Pacific world cities to emerge as some control and command centers embedded in world city network.
\end{abstract}

Keywords-Control and Command Center; World City Network; Globalization; Multinational Companies Headquarters; Forbes Global 2000

\section{INTRODUCTION}

In the dynamic context of globalization, headquarter function of the predominant multinational companies (MNC) is an integral part of world city studies. In line with contemporary transformation of urbanization and industrialization, it is conspicuous that the majority of MNC tend to concentrate on some world cities, particularly pertinent to the economic base and the vibrant market environment of these cities. Hence, the study of some control and command centers' formation with reference to their headquarter function is perceived to be increasingly significant, especially related to their network connections on the basis of the world city network. Based on pioneering studies of global urban hierarchy [6], global city and advanced producer services formation [10] command and control function of world city is elucidated in many articles, notably for the presences of the MNC headquarters in these cities [1,7,17]. Due to the spatial organization of MNC headquarters, [15] it is proposed that control and command center formation is closely associated with the headquarter status of the city. In spite of the 2008 financial crisis, geo-economic restructuring is transited at a staggering rate, and the financial sector still maintains its preeminent position $[16,18]$.

Previous studies on control and command centers tend to restrict to Europe [14] and North America [13]. In this article, we will explore the control and command function of AsiaPacific cities with regard to their Multinational Company's headquarters agglomeration. In addition to finding the control and command functions of Asian-Pacific world city based upon the hierarchical method, we also seek to explore control and command function embedded in world city network with regard to its relevant connectivity in Asia-Pacific region. Following [2], since the majority of world city study tends to focus on the hierarchical structure of urban relationship based upon the attributed data, this form of study is usually ascribed to the dearth of relational data $[8,12]$. In this sense, some scholars are intended to explore the increasingly inter-city connections in the age of globalization. This pattern of network structure is presented in the pattern of seamless office network of global business firms, and the details are explored in $[5,13]$. Most importantly, this ramification of business network conceptualizes the inter-city connections in the form of world city network. In this research, we would examine the network connectivity of Asia pacific city embodied in the world city network.

\section{METHODOLOGY}

\section{A. Control and Command Center Model}

This article applies the control and command center model from the Globalization and world city research network (GaWC) by utilizing the dataset 26 from GaWC's website based upon "Forbes global 2000" information of year 2011 [3, 4]. According to this model, we can straightforwardly examine the general ranking of the leading 2000 firms in the world and the spatial distribution of their headquarters in the global 
territory. Specifically, the general ranking is attributed to the comprehensive information of sales, profits and market values of Forbes database and headquarters' distribution is derived from company websites, and some business websites, as well as Google Map. In practice, in order to avoid some hidden and ambiguous results in this research, we will draw on the previous GaWC experience in the control and command center research. Generally, since bunds of companies' headquarters are not concentrated in the core city area, they are decentralized in the suburban locations or satellite city of core city. In this multi-layered analysis, we will initiate the metropolitan area to replace the concept of city in our research. For instance, as some headquarters in Kuala Lumpur of Malaysia are located in its satellite city Petaling Jaya or its neighboring state Selangor, hence, we will qualify a notable metropolitan area Kuala Lumpur-Petaling Jaya-Selangor to represent our sourced headquarters in the Kuala Lumpur area. In other words, in this research, city is replaced by its corresponding metropolitan area for deep analysis.

According to these two streams of information, we can clearly calculate the quantity of Forbes global 2000 companies in each Asia-Pacific metropolitan area. In line with the quantitative calculation, we will incorporate firm size and other essential information in our analysis. Eventually, a control and command index ( CCI) is proposed in our article which derived from GaWC research network. Along with general hierarchical ranking, CCI is able to simplify the ranking of the control and command centre in Asia-pacific area with reference to a more rigorous evaluation method. Specifically, a measurement of linear combination about control and command index is not restricted to simple count of headquarters and one variable in a city. In such an index, we invariably approach some other dominant variables in the Forbes global 2000 database. Hence, this index is equal to the sum of percentage of four critical variables along with quantity of headquarters, which are revenues, assets, profit, as well as market value. The major formula is summarized as followings:

$$
C C I_{X, Y}=\sum_{i=1}^{n} \frac{R_{i, x, y}+A_{i, x, y}+P_{i, x, y}+M W_{i, x, y}}{4}
$$

Where $R_{i, x, y}$ refers to the percentage of revenues derived from total database; $A_{i, x, y}$ is the percentage of assets in the total database, $P_{i, x, y}$ and $M W_{i, x, y}$ are the percentage of profit and market value from the total database respectively. Apart from four variables, $i$ denotes the quantity of Global 2000 company headquarters in a city and $n$ represents the total number of headquarters in city $x$ in given year $y$. In addition to formal specification of control and command centre model, GaWC research network also simplify the 80 industries in Forbes global 2000 database into 10 ordinary sectors using the Global Industrial Classification Standard (GICS). In our research, we homogenise the Asia-pacific cities with reference to 10 ordinary sectors in order to find the sectoral structure of control and command centres in the Asia-Pacific region

\section{B. Interlocking City Network Model}

Generally, world city tends to deemed as a global service center integrated in the global economy, interlocking city network model is initiated in this research so that we could measure the global network connectivity of Asia-Pacific cities embedded in world city network. Building upon the model specification of GaWC research network $[13,14]$ and theory of world city network, we specify the model in the matrix of $V_{i j}$. Clearly, this matrix demonstrates the presence of $j$ firms in $i$ cities, and $V_{i j}$ is considered as the service value of firm $j$ with reference to city $i$; practically, the network connectivity of each paired cities are indicated as followings:

$$
R_{a b, j}=V_{a j} \times V_{b j}
$$

Where $V_{a j}$ and $V_{b j}$ refer to service value of firm $\mathrm{j}$ with regard to city $a$ and city $b$ in the city dyad network.

Apart from the paired city connectivity derived from one firm, we also need to gauge the aggregate city connectivity of all advanced producer services firms between city $a$ and $b$ in the interlocking city network model. The formula is developed in details as followings:

$$
R_{a b}=\sum R_{a b, j}
$$

Finally, in order to identify the global network connectivity of single city drawn from the interlocking city network model. The formula is elucidated below:

$$
G N C_{a}=\sum R_{a i}(a \neq i)
$$

Where $G N C_{a}$ is network connectivity of city a with regards to all cities and all advance producer services firms. Therefore, the result is indicated in the relative value in this Table $I$ in terms of the connectivity of top 10 cities in the Asia-pacific region. Based upon model specification of interlocking city network, GaWC research network collect the relational data for the subsequent calculation and analysis. In order to produce the interlocking network about location strategy of multinational companies in the global scale, the notable of data collection procedure is constituted of three parts, which are detailed as followings: At the beginning, GaWC research network select the 526 cities covering all of global arenas. These cities tend to be some capital cities, metropolises and some other dominant cities of each country. In addition to city selection, GaWC implemented the procedure to select the firms for constructing a matrix. The criterion is determined by the ranking of firm size. Consequently, a dataset of global producer service firms are qualified with the branches above 15 different cities and at least one branch in each of the three global arenas, which are East Europe, North America and Asia Pacific. Based upon the rigorous detection process, a number of 175 leading advanced producer service firms are identified in this database. In line with the cities and firms selection, meanwhile, we also assign the service value in terms of an advanced producer services firm in a city. Two kind of secondary information are collected by GaWC research network. The first information refers to the size of firm office or branch in a city, notably for the number of practitioners and quantity of offices in a city. Besides, the second spectrum of information is collected based on extra- 
locational functions of branches or offices in a city, for instance, national headquarter, regional headquarter and local branches. According to the above two types of information, we assign the service value of a firm's presence in a city covering a range between 0 and 5. Specifically, a city with a firm's headquarter is assigned with 5 whereas a normal office or branch is deems as 2 in the scoring system. Besides, if an office with no partner, the mark will reduce to 1 . In contrast, if an office possesses large pattern of size, the score is increased to 3. Finally, an office is considered as regional headquarters, the mark will be 4 .

\section{RESULTS AND DISCUSSION}

Table I summarizes the major indicators of top 10 Asiapacific control and command centers based upon the Forbes 2000 corporations' headquarters' ranking. This table encompasses the information of pilot study about number of sectors from GICS, number of firms' headquarters, control and command index, as well as the network connectivity of each city. Accordingly, we can demonstrate that the Tokyo is the leading control and command center in the Asia-Pacific region. Based on this table, it is conspicuous that this world city possesses the highest quantity of the Global 2000 companies' headquarters and number of GICS sectors. Clearly, the quantity of headquarters is twice over the second position city- Seoul. This trend of hierarchy is attributed to the robust economic base and multifarious industry structure of Japan in the world economy. Not surprisingly, this diversity of industry and economy development of Japan enables its strategic center (Tokyo) to attract huge amount of multinational companies pertaining to Japan's economy development. Apart from Tokyo' irreplaceable position in the Asia-Pacific world city network, some other capital cities of emerging counties are also embodied in an incipient power integrated in the Asia-Pacific economy. In this situation, we could find that Korea, Hong Kong and China aggressively strive to attract the MNC headquarters in their capital cities in the era of globalization. This unprecedented framework of the MNC agglomeration in some capital cities tend to be associated with a structural amalgam of spatial dispersal and global integration in these countries [9, 11]. Since these capital cities entail a network power in the world city network, this network power significantly contributes to its control and command center formation. In other words, network power is correlated with the control and command center development.
In general, the ranking of connectivity has implications on the power of a city; meanwhile, instructional power is the major determinants for the control and command center development [14]. In this article, we will examine the interrelationship between the control and command index and network connectivity. According to Table I, we could find that the ranking of control and command index tends to epitomize an inconsistent correlation with the network connectivity. Clearly, some cities maintain a conspicuous higher ranking in the control and command index whereas they are only featured a lower ranking in the batch of network connectivity. For instance, Osaka is classified in this group with a lower network connectivity of only 18.79 as compared to other competitors in the world city network. With the exception of some slight distinctions between CCI and network connectivity in most cities, Hong Kong performs a notable position in the status of highest connectivity of world city network in spite of relative average ranking in the CCI. Hence, the preliminary glimpse of general ranking of control and command is not enough to discover the intrinsic hierarchical structure of control and command center embedded in world city network, the next section attempts to elucidate the sectoral structure of control and command center embedded in the world city network based upon GICS sectors. According to Table II., we can find Tokyo is by far the most dominant control and command center in the majority sectors in the face of the competition with other Asia-Pacific cities. The successful of Tokyo in the majority rankings tends to attributed to its unprecedented economic power, industrialization and urbanization in the context of globalization. Apart from Tokyo, Beijing is another critical city in several spectrums of sectoral ranking, notably for the financial and utilities sectors. Beijing has powerful financial and utilities market in the Asian arena as so far, possibly reflecting the trend of rapid economic transformation, industrial consolidation, as well as urban restructuring of China. On the other hand, this sectoral ranking also implies that Beijing is the preeminent world city in the global scale. Apart from Tokyo and Beijing, some other cities are embodied by a complementary ranking in the different sectors, which means some cites are ranking higher in one sector whilst they are possible ranking lower in other sectors, the other competitors will replace or complement its position in the respective sectoral ranking.

TABLE I. TOP 10 HEADQUARTER CITIES IN ASIA-PACIFIC REGION

\begin{tabular}{|c|c|c|c|c|c|}
\hline Ranking & City & No of GICS sectors & No of HQs & CCI & $\begin{array}{c}\text { Network Connectivity } \\
\text { London=100 }\end{array}$ \\
\hline 1 & Tokyo & 10 & 154 & 23.15 & 65.22 \\
\hline 2 & Seoul & 9 & 60 & 7.16 & 53.42 \\
\hline 3 & Hong Kong & 8 & 48 & 8.11 & 77.91 \\
\hline 4 & Beijing & 7 & 45 & 18.68 & 62.19 \\
\hline 5 & Taipei & 6 & 27 & 2.55 & 43.88 \\
\hline 6 & Mumbai & 9 & 26 & 3.28 & 59.42 \\
\hline 7 & Osaka & 7 & 23 & 2.70 & 18.79 \\
\hline 8 & Sydney & 5 & 21 & 3.57 & 62.91 \\
\hline 9 & Shanghai & 6 & 19 & 2.49 & 64.52 \\
\hline 10 & Singapore & 5 & 18 & 2.36 & 67.63 \\
\hline
\end{tabular}




\begin{tabular}{|c|c|c|c|c|c|c|c|c|c|c|c|c|}
\hline & & & & & & & & & \\
\end{tabular}

\section{CONCLUSION}

Based upon progressive hierarchical analysis of control and command centers in Asia-Pacific arena, the fascinating hierarchical structure of control and command centers were clearly corroborated. Control and command centers are the major cities that facilitate the development of multinational companies in different countries with access to global market, espousing to the international network. Accordingly, the hierarchical structure of control and command center in AsiaPacific area can be classified into 3 tiers. Tokyo is the irreplaceable apex location in this urban hierarchy inferred by considering general ranking and sectoral ranking. The enormous quantity of multinational companies is attributed to a vast number of foreign direct investments. On the other hand, since the majority of multinational companies' headquarters tend to agglomerate in some financial centers or industrial centers, the spectacular updating of Japanese economy have moulded its capital city (Tokyo) to sustain the financial center and industrial center in the Asia-Pacific region. Thus, all of above centripetal forces contribute to higher control and command index and network connectivity of Tokyo. Apart from the Tokyo's position in the urban hierarchy of control and command centers, meanwhile, Seoul, Hong Kong and Beijing maintain their second tier's position in the hierarchy. Seoul and Hong Kong are two cities with the consolidated economic base in the Asia region so that they can facilitate the high amount of multinational company regional headquarters. The only exception is Beijing, due to the fact of the rising of industrial transformation of Chinese industries, and west to east shift of world economy. Chinese economy is overwhelmingly acquiring benefits from these opportunities. Consequently, the Apex city of China (Beijing) will attain more chances to linkage with other world cities and attracting of MNC. These all are indispensable benefits affecting the control and command center formation in Beijing. In addition to first and second tiers of leading control and command centers embedded in world city network, the third tier is characterized by some other capital cities and metropolises in some Asia emerging economy, as well as some developed counties, such as Australia and Singapore.

Furthermore, with the exception of hierarchical structure of control and command centers in Asia-Pacific region, spatial structure is also essential to be explored. The spatial structure of control and command centers could reflect a west-east disparities of spatial pattern, which means all of leading control and command are concentrated in the East Asia and Pacific regions, there are no candidates are reflected in the West and Middle Asia regions. In spite of fuzzier borders for the space of flow and transnational economy, Asia- Pacific region still indicates a tendency of uneven regional development. Therefore, the majority of multinational companies' headquarters are concentrated in East Asia district albeit some prosperous counties in Middle-East area. This uneven spatial disparity corroborates the importance in terms of location and information of the control and command center formation. Since East Asia and Pacific areas have the convenient location for the transportation and infrastructure development, as well as proximity to global and regional information, they attract the higher quantity of MNC headquarters thereby enhancing their control and command development.

Although this empirical study identifies the hierarchical structure and spatial structure of control and command in the Asia-Pacific region, there still exits some deficiency. In the future research, we will conduct some other spatial analysis and quantitative analysis methods to discover the spatial-temporal structure of control and command centers embedded in world city network.

\section{ACKNOWLEDGMENT}

The authors would like to thank Universiti Sains Malaysia for providing financial assistance through the USM Fellowship to 
conduct this research smoothly. The data were produced by G. Csomós and constitute Data Set 26 of the Globalization and World Cities (GaWC) Research Network (http://www.lboro.ac.uk/gawc/) publication of inter-city data.

\section{REFERENCES}

[1] A. Alderson, J. Beckfield, "Power and Position in the World City System", American Journal of Sociology, Vol. 109, No. 4, pp. 811-851, 2004

[2] J. V. Beaverstock, R. G. Smith, P. J. Taylor, "World-City Network: A New Metageography?", Annals of the Association of American Geographers, Vol. 90, No. 1, pp. 123-134, 2000

[3] G. Csomós, "The command and control centers of the United States (2006/2012): An analysis of industry sectors influencing the position of cities", Geoforum, Vol. 50, pp. 241-251, 2013

[4] G. Csomós, B. Derudder, "European cities as command and control centres, 2006-11", European Urban and Regional Studies, Vol. 21, No. 3, pp. 345-352, 2014

[5] B. Derudder, P. J. Taylor, F. Witlox, G. Catalano, "Hierarchical tendencies and regional patterns in the world city network: A global urban analysis of 234 cities", Regional Studies, Vol. 37, No. 9, pp. 875886, 2003

[6] J. Friedmann, "The World City Hypothesis. Development and Change", Vol. 17, No. 1, pp. 69-83, 1986

[7] [7] Godfrey, B. J., \& Zhou, Y. , "Ranking world cities: Multinational corporations and the global urban hierarchy. Urban Geography", Vol. 20, No. 3, pp. 268-281, 1999

[8] Z. Li, S. R. S. Dawood, "World City Network in China: A Network Analysis of Air Transportation Network. Modern Applied Science", Vol. 10, No. 10, pp. 213-223, 2016
[9] "World Cities Formation in China: A Comparative Study of Five PreEminent Cities", Mediterranean Journal of Social Sciences, Vol. 7 No.6, pp. 387-396, 2016

[10] S. Sassen, "The global city: strategic site/new frontier", American Studies, Vol. 41, No. 2/3, pp. 79-95

[11] S. Sassen,T he global city: New York, London, Tokyo, Princeton University Press, 2001

[12] J. R. Short, Y. Kim, M. Kuus, H. Wells, "The dirty little secret of world cities research: Data problems in comparative analysis", International Journal of Urban and Regional Research, Vol. 20, No. 4, pp. 697-717, 1996

[13] P. J. Taylor, "Specification of the world city network", Geographical Analysis, Vol. 33 No. 2, pp. 181-194, 2001

[14] P. J. Taylor, G. Catalano, D. R. F. Walker, "Measurement of the world city network", Urban Studies, Vol. 39, No. 13, pp. 2367-2376, 2002

[15] P. J. Taylor, G. Csomós, "Cities as control and command centres: Analysis and interpretation", Cities, Vol. 29, No. 6, pp. 408-411, 2012

[16] P. J. Taylor, P. Ni, B. Derudder, M. Hoyler, J. Huang, F. Lu, D. Bassens, "The way we were: command-and-control centres in the global spaceeconomy on the eve of the 2008 geoeconomic transition", GaWC Research Bulletin, pp. 289, 2008

[17] S. X. B. Zhao, J. M. Cai, L. Zhang, "Asymmetric information as a key determinant for locational choice of MNC headquarters and the development of financial centers: A case for China", China Economic Review, Vol. 16, No. 3, pp. 308-331, 2005

[18] L. Zeyun, S. R. S. Dawood, "Development of the Regional Financial Centers in China: A Quantitative Study Based on the Province-level Data", Mediterranean Journal of Social Sciences, Vol. 7, No. 3 S1, pp. 374-382, 2016 